\title{
Impact of Morbid Obesity on Left Ventricular Assist Device Support and Heart Transplantation
}

\author{
Sophia E Cohen, MD, Ryan M Johnson and Mohammed Quader, MD* \\ Division of Cardiothoracic Surgery, Virginia Commonwealth University, USA
}

\begin{abstract}
Background: Limited data suggests that morbid obesity (Body Mass Index- BMI $>35 \mathrm{~kg} / \mathrm{m}^{2}$ ) increases complications after left ventricular assist device (LVAD) implantation and after heart transplantation (HTx). We comprehensively compared LVAD and heart transplantation (HTX) outcomes in patients with and without morbid obesity.

Methods: Society of Thoracic Surgeons (STS) and Interagency Registry for Mechanically Assisted Circulatory Support (INTERMACS) data on LVAD and HTx surgeries at our institution from 2008-2014 was analyzed. Patients were divided into two groups, $\mathrm{BMI} \geq 35$ and $\mathrm{BMI}<35$.

Results: Of the 157 LVADs implanted, 121 (77\%) were in patients with a BMI < 35 and 36 (23\%) were in patients with a BMI $\geq 35$. Morbidly obese patients were younger ( $47 \pm 12.7$ yrs vs. $55 \pm 13.4 \mathrm{yrs}$ ), had more females ( $44 \%$ vs. $24 \%$ ), had higher right heart catheterization pressures, and fewer prior myocardial infarctions ( $22 \%$ vs. $46 \%$ ), all $p<0.05$. Preoperative morbidities, INTERMACS class, and LVAD implantation designation were comparable between both groups. The BMI $\geq$ 35 group had more postoperative and device complications, but only bleeding requiring reoperation $(42 \%$ vs. $22 \% p=$ 0.03 ) and mean number of driveline infections were statistically significant ( $2.4 \pm 1.7$ vs. $1.2 \pm 0.5 p=0.02)$. At a mean follow-up of $27.3 \pm 20.5$ months, fewer morbidly obese patients received a HTx $(19 \%$ vs. $33 \% p=0.15)$ after relatively longer wait times ( $619 \pm 372$ vs. $403 \pm 342$ days, $p=0.1)$. After $H T x$, morbidly obese patients had more reoperations $(57 \%$ vs. $15 \% \mathrm{p}=0.03)$.
\end{abstract}

Conclusions: Morbidly obese patients requiring LVAD support encounter higher postoperative complications and wait longer for heart transplantation, however in selected group of patients HTx and graft survival is comparable.

\begin{abstract}
Abbreviations
LVAD: Left Ventricular Assist Device; HTx: Heart Transplantation; CHF: Congestive Heart Failure; BTT: Bridge to Transplantation; BMI: Body Mass Index; ISHLT: International Society for Heart and Lung Transplantation; MCS: Mechanical Circulatory Support; DT: Destination Therapy; BTR: Bridge to Recover; RVAD + LVAD: BiVAD; STS: Society of Thoracic Surgeons; INTERMACS: Interagency Registry for Mechanically Assisted Circulatory Support; CABG: Coronary Artery Bypass Graft; PRA: Panel-Reactive Antibody; UNOS: United Network for Organ Sharing
\end{abstract}

\section{Introduction}

Congestive heart failure (CHF) affects 5.1 million people in the United States with over 550,000 new cases per year and contributes to about 287,000 deaths per year [1]. The current standard of treatment for patients with end stage heart failure is heart transplantation ( $\mathrm{HTx}$ ), however, the pool of viable donor hearts is not sufficient to meet the needs of patients with end stage heart failure [2]. Therefore, when a donor heart becomes available, it is imperative to allocate it to a patient who is most likely to benefit. The discrepancy between supply and demand of donor hearts, has led to the increasing use of continuous flow left ventricular assist devices (LVADs) as a bridge to transplantation (BTT) $[3,4]$.

An important factor in patient selection for both LVAD support and HTx is patient's body mass index (BMI). The 2013 International Society for Heart and Lung Transplantation
(ISHLT) guidelines for mechanical circulatory support (MCS) state that "surgical risk and attendant comorbidities must be carefully considered prior to MCS in the morbidly obese patient (BMI $\geq 35$ ) [5]".

The ISHLT published listing criteria for HTx in 2016 states

*Corresponding author: Mohammed Quader, Division of Cardiothoracic Surgery, Virginia Commonwealth University, 1200 East Broad St, West Hospital 7th Floor, Richmond VA 23298, USA, Tel: 804-828-4641, Fax: 804 828-4641

Accepted: July 26, 2019

Published online: July 28, 2019

Citation: Cohen SE, Johnson RM, Quader M (2019) Impact of Morbid Obesity on Left Ventricular Assist Device Support and Heart Transplantation. J Transplant Surg 2(1):33-40 
that candidates should lose weight to achieve a $\mathrm{BMI} \leq 35$ $\mathrm{kg} / \mathrm{m}^{2}$ before listing for cardiac transplant because a pretransplant $\mathrm{BMI}>35$ is associated with a worse outcome after cardiac transplantation [6]. However, studies supporting this data are conflicting and limited [7-12].

The aims of this study are to compare patient outcomes with and without morbid obesity, who received LVAD and subsequent HTx. The study outcomes included a) postoperative LVAD morbidity and mortality; b) wait time to heart transplant; c) long-term LVAD complications; d) post-heart transplant morbidity and mortality; e) survival after HTX.

This study is important for 3 reasons. Limited number of studies have followed morbidly obese patients through LVAD and heart transplantation, which is important as increasingly more obese patients are being bridged with an LVAD. Secondly, the ISHLT listing criteria for heart transplantation were only supported by level $C$ evidence, which is by a consensus opinion of experts and not based on scientific data. Lastly, although weight loss to a BMI of $<35$ is recommended before listing, weight loss is difficult and unattainable for many patients with advanced heart failure [13].

\section{Methods}

The study population was comprised of 157 patients with advanced heart failure who received an LVAD (HeartMate II - Thoratec Corp, Pleasanton, California, or HeartWare HVAD, Framingham, Massachusetts) at Virginia Commonwealth University from December 2008 through January 2014. All indications for LVAD implantation, BTT, destination therapy (DT) and bridge to recover (BTR) were included in the study. We excluded patients who were under 18-years-old, who were undergoing repeat LVAD implantation for any reason, and those who had a planned BiVAD (RVAD + LVAD) implantation.

We divided the patients into two groups based on $\mathrm{BMI}$ before LVAD surgery; a morbidly obese group (BMI $\geq 35 \mathrm{~kg}$ / $\mathrm{m}^{2}$ ) and a non-morbidly obese group (BMI $\left.<35 \mathrm{~kg} / \mathrm{m}^{2}\right)$. We used a cut-off BMI of 35 per National Institutes of Health directive guidelines [14]. Our hospital's Institutional Review Board approved this study and the need for individual informed consent was waived.

We retrospectively collected data on each patient from the Society of Thoracic Surgeons (STS) and Interagency Registry for Mechanically Assisted Circulatory Support (INTERMACS) databases as well as reviewed patient's electronic medical records. A detailed analysis of the data was performed with SAS 9.3 software (SAS Institute Inc, Cary, NC). Categorical variables were analyzed using the Fisher's exact test and were reported as percentages. Continuous variables were analyzed using the Wilcoxon rank sum test or the Student's t-test and were reported as mean or median values with standard deviations. Statistical comparisons were two-tailed and a P-value of $<0.05$ was considered statistically significant. Survival analysis was determined by the Kaplan-Meier method and survival between the two groups was performed using the log-rank test.

\section{Results}

Baseline LVAD patient characteristics are summarized in Table 1. Of the 157 patients who received an LVAD, 36 (23\%)

Table 1: Pre-Operative patient characteristics undergoing CF-LVAD Implantation.

\begin{tabular}{|c|c|c|c|}
\hline \multirow[b]{2}{*}{ Pre-Operative Variable } & \multicolumn{2}{|l|}{ BMI kg/m² } & \multirow[b]{2}{*}{$P$ value } \\
\hline & $\begin{array}{l}\geq 35 \\
n=36(23 \%)\end{array}$ & $\begin{array}{l}<35 \\
n=121(77 \%)\end{array}$ & \\
\hline Age in years, mean $\pm S D$ & $47 \pm 12.7$ & $55 \pm 13.4$ & 0.001 \\
\hline Gender-Female, \% & 44 & 24 & 0.04 \\
\hline $\mathrm{BMI}$, mean \pm SD & $41.6 \pm 5.5$ & $27.8 \pm 4.1$ & \\
\hline BMI, median (range) & $40.7(35.3,58.5)$ & $28(17.6,34.9)$ & \\
\hline Cerebrovascular Disease, \% & 5.6 & 17 & 0.11 \\
\hline Diabetes, \% & 44 & 47 & 0.85 \\
\hline Hypertension, \% & 78 & 68 & 0.30 \\
\hline Renal Failure-Dialysis, \% & 3 & 7 & 0.46 \\
\hline History of Cigarette Smoking, \% & 21 & 30 & 0.38 \\
\hline Prior MI, \% & 22 & 46 & 0.01 \\
\hline Arrhythmia, \% & 36 & 63 & 0.007 \\
\hline Previous CABG, \% & 3 & 17 & 0.03 \\
\hline Hemoglobin A1C Prior to Surgery, mean \pm SD & $7.2 \pm 2.2$ & $6.6 \pm 1.5$ & 0.34 \\
\hline Hematocrit- $\mathrm{mg} / \mathrm{dl}$, mean $\pm \mathrm{SD}$ & $33.8 \pm 6.0$ & $34.9 \pm 6.6$ & 0.49 \\
\hline Total Bilirubin $\mathrm{mg} / \mathrm{dl}$, mean \pm SD & $1.2 \pm 1.2$ & $1.2 \pm 0.8$ & 0.09 \\
\hline MELD Score, mean \pm SD & $13.4 \pm 4.5$ & $13.9 \pm 5.6$ & 0.90 \\
\hline Creatinine $\mathrm{mg} / \mathrm{dl}$, mean $\pm \mathrm{SD}$ & $1.4 \pm .6$ & $1.3 \pm 0.6$ & 0.30 \\
\hline
\end{tabular}


Citation: Cohen SE, Johnson RM, Quader M (2019) Impact of Morbid Obesity on Left Ventricular Assist Device Support and Heart Transplantation. J Transplant Surg 2(1):33-40

\begin{tabular}{|c|c|c|c|}
\hline Ejection Fraction, mean \pm SD & $15.4 \pm 5.1$ & $15.1 \pm 5.6$ & 0.60 \\
\hline \multicolumn{4}{|l|}{ Right Heart Catheter Pressures (mmHg) } \\
\hline Right atrial pressure mean & $18.3 \pm 8.8$ & $13.3 \pm 5.7$ & 0.004 \\
\hline Pulmonary artery systolic pressure & $61.4 \pm 11.6$ & $55.4 \pm 13.4$ & 0.02 \\
\hline Pulmonary artery diastolic pressure & $34.5 \pm 8.3$ & $30.2 \pm 8.3$ & 0.01 \\
\hline Pulmonary artery mean pressure & $44.7 \pm 7.9$ & $38.7 \pm 9.6$ & 0.001 \\
\hline PCWP & $32.4 \pm 9.0$ & $27.8 \pm 8.0$ & 0.01 \\
\hline PVR & $3.2 \pm 1.9$ & $3.5 \pm 1.7$ & 0.13 \\
\hline INTERMACS Class & & & 0.13 \\
\hline $1, \%$ & 11 & 33 & \\
\hline $2, \%$ & 37 & 24 & \\
\hline $3, \%$ & 33 & 24 & \\
\hline $4, \%$ & 19 & 18 & \\
\hline Device & & & 0.42 \\
\hline HeartMate II, \% & 81 & 87 & \\
\hline HeartWare HVAD, \% & 19 & 13 & \\
\hline LVAD Designation & & & 0.68 \\
\hline Bridge to Transplantation, \% & 61 & 61 & \\
\hline Destination, \% & 36 & 31 & \\
\hline Bridge to Recovery, \% & 3 & 7 & \\
\hline Status & & & 0.93 \\
\hline Elective, \% & 8 & 9 & \\
\hline Urgent, \% & 83 & 84 & \\
\hline Emergent, \% & 8 & 7 & \\
\hline
\end{tabular}

BMI: Body Mass Index; MI: Myocardial Infarction; MELD: Model for End-stage Liver Disease; SD: Standard Deviation; PCWP: Pulmonary Capillary Wedge Pressure; PVR: Pulmonary Vascular Resistance; INTERMACS: Interagency Registry for Mechanically Assisted Circulatory Support.

Table 2: In Hospital Post-Operative outcomes of patients who received CF-LVAD implantation.

\begin{tabular}{|c|c|c|c|}
\hline \multirow[b]{2}{*}{ Post-operative Variable } & \multicolumn{2}{|l|}{ BMI kg/m² } & \multirow[b]{2}{*}{$P$ value } \\
\hline & $\begin{array}{l}\geq 35 \\
n=36(23 \%)\end{array}$ & $\begin{array}{l}<35 \\
n=121(77 \%)\end{array}$ & \\
\hline Operative Mortality, \% & 20 & 11 & 0.25 \\
\hline Length of hospital stay, mean \pm SD & $39.6 \pm 26.3$ & $47.0 \pm 27.3$ & 0.08 \\
\hline Total ventilation hours, mean \pm SD & $138.2 \pm 148.3$ & $153.2 \pm 232.7$ & 0.67 \\
\hline In Hospital Post-op Events, \% & 94 & 88 & 0.37 \\
\hline Reoperation due to bleeding, \% & 42 & 22 & 0.03 \\
\hline Stroke, \% & 8 & 2 & 0.13 \\
\hline Multi System Failure, \% & 14 & 5 & 0.13 \\
\hline Pneumonia, \% & 6 & 13 & 0.25 \\
\hline New onset Renal Failure, \% & 28 & 19 & 0.24 \\
\hline Sepsis, \% & 8 & 11 & 1 \\
\hline Surgical Site Infection, \% & 6 & 7 & 1 \\
\hline Delayed Sternal Closure, \% & 44 & 31 & 0.16 \\
\hline 30-day Survival, \% & 81 & 90 & 0.15 \\
\hline
\end{tabular}

were in $\mathrm{BMI} \geq 35$ and 121 (77\%) were in $\mathrm{BMI}<35$ groups. The and $27.8 \pm 4.1$ respectively. Our study population included mean $\mathrm{BMI}$ of the $\mathrm{BMI} \geq 35$ and $<35$ groups was $41.6 \pm 5.5$, a range of $\mathrm{BMl}^{\prime}$ : underweight $\mathrm{BMI}<18.5$ ( $\mathrm{n}=3,0.02 \%$ ), 
Citation: Cohen SE, Johnson RM, Quader M (2019) Impact of Morbid Obesity on Left Ventricular Assist Device Support and Heart Transplantation. J Transplant Surg 2(1):33-40

normal weight BMI 18.5-24.99 $(n=28,17.83 \%)$, overweight BMI 25-29.99 ( $n=48,30.57 \%$ ), obesity class I 30-34.99 ( $n=$ $42,26.75 \%)$, obesity class II 35-39.99 ( $n=16,10.19 \%)$, and obesity class III > 40 ( $n=20,12.74 \%)$. Obesity class II and III were included in morbidly obese group.

The morbidly obese group was younger by an average of 8 years ( $47 \pm 12.7$ yrs. vs. $55 \pm 13.4$ yrs.), had more females (44\% vs. $24 \%$ ) and had higher right heart catheter pressures, with all $p$-values $<0.05$. The morbidly obese group had fewer prior myocardial infarctions ( $22 \%$ vs. $46 \%$ ), arrhythmias ( $36 \%$ vs. $63 \%)$ and previous coronary artery bypass graft (CABG) surgeries ( $3 \%$ vs. $17 \%$ ) with all $p$-values $<0.05$. The other preoperative comorbidities were comparable between the two groups, including diabetes, hypertension, cerebrovascular disease and renal failure. LVAD type, implantation designation and basic laboratory values were comparable between the two groups. Morbidly obese patients had a lower prevalence of INTERMACS class I patients ( $11 \%$ vs. 33\%), however overall INTERMACS class distribution between the two groups was comparable.

Post-operative outcomes following LVAD surgeries are summarized in Table 2. Both groups had comparable post-op ventilation hours, length of stay, 30-day survival and in hospital post-operative events. In hospital post-operative events included stroke, multi-system organ failure, sepsis, surgical site infection, pneumonia and new onset renal failure. Morbidly obese patients had higher post-operative bleeding requiring reoperation ( $42 \%$ vs. $22 \% ; p=0.03$ ).

Device specific complications in all LVAD patients are summarized in Table 3. Throughout the average follow-up time of $1.55 \pm 1.3$ years, overall device related complications were comparable between the two groups, including driveline infection, stroke and GI bleed. However, morbidly obese patients trended towards increased device thrombosis $(26.5 \%$ vs. $12 \% ; p=0.056)$ and hemolysis ( $25.7 \%$ vs. $11.1 \% ; p=0.05)$. In the subset of patients who had driveline infection, more morbidly obese patients had recurrent driveline infections $(2.4 \pm 1.7$ vs. $1.2 \pm 0.5 ; p=0.02)$.

Device specific complications in BTT patients are summarized in Table 4. There were 96 patients with LVAD designation as BTT, among these, 22 patients had $\mathrm{BMI} \geq 35$ and 74 had $\mathrm{BMI}<35$. Patients with a $\mathrm{BMI} \geq 35$ trended towards a longer waiting time to HTx ( $619 \pm 372$ days vs. $403 \pm 342$ days; $p=0.096)$. While on the HTx wait list, both groups had comparable device related complications.

Characteristics of patients who underwent HTxare summarized in Table 5. Of the 96 patients in the BTT group, only $47(49 \%)$ received a $\mathrm{HTx}$, of these 7 were in $\mathrm{BMI} \geq 35$ and

Table 3: Complications during LVAD support: All LVAD patients.

\begin{tabular}{|c|c|c|c|}
\hline \multirow[b]{2}{*}{ Variable } & \multicolumn{2}{|l|}{ BMI kg/m² } & \multirow[b]{2}{*}{$P$ value } \\
\hline & $\begin{array}{l}\geq 35 \\
n=36(23 \%)\end{array}$ & $\begin{array}{l}<35 \\
n=121(77 \%)\end{array}$ & \\
\hline Average years of LVAD support, mean \pm SD & $1.5 \pm 1.3$ & $1.6 \pm 1.3$ & \\
\hline Device Related complications, \% & 65 & 62 & 0.84 \\
\hline Driveline Infection, \% & 24 & 26 & 1 \\
\hline Device Thrombosis, \% & 27 & 12 & 0.056 \\
\hline Hemolysis, \% & 26 & 11 & 0.05 \\
\hline Stroke, \% & 24 & 12 & 0.10 \\
\hline GI Bleed, \% & 20 & 27 & 0.51 \\
\hline Number of Driveline Infections, mean \pm SD & $2.4 \pm 1.7$ & $1.2 \pm 0.5$ & 0.02 \\
\hline
\end{tabular}

Table 4: Bridge to transplant patients.

\begin{tabular}{|c|c|c|c|}
\hline \multirow[b]{2}{*}{ Variable } & \multicolumn{2}{|l|}{$\mathrm{BMI} \mathrm{kg} / \mathrm{m}^{2}$} & \multirow[b]{2}{*}{$P$ value } \\
\hline & $\begin{array}{l}\geq 35 \\
n=22\end{array}$ & $\begin{array}{l}<35 \\
n=74\end{array}$ & \\
\hline \multicolumn{4}{|l|}{ Device Related complications } \\
\hline Driveline Infection, \% & 33 & 24 & 0.40 \\
\hline Device Thrombosis, \% & 24 & 13 & 0.3 \\
\hline Hemolysis, \% & 29 & 13 & 0.096 \\
\hline Stroke, \% & 24 & 11 & 0.16 \\
\hline GI Bleed, \% & 19 & 19 & 1 \\
\hline Wait to $\mathrm{HTx}$ (days), mean \pm SD & $619 \pm 372$ & $403 \pm 342$ & 0.096 \\
\hline Wait to HTx (days), median & $469(128,1302)$ & $316(36,1573)$ & 0.10 \\
\hline
\end{tabular}

HTx: Heart Transplantation; BTT: Bridge to Transplantation. 
Citation: Cohen SE, Johnson RM, Quader M (2019) Impact of Morbid Obesity on Left Ventricular Assist Device Support and Heart Transplantation. J Transplant Surg 2(1):33-40

Table 5: Heart transplantation perioperative characteristics.

\begin{tabular}{|c|c|c|c|}
\hline \multirow[b]{2}{*}{ Variable } & \multicolumn{2}{|l|}{ BMI kg/m² } & \multirow[b]{2}{*}{$P$ value } \\
\hline & $\geq 35 n=7$ & $<35 n=40$ & \\
\hline $\mathrm{HTx}$ received in BTT, \% & $32(n=7)$ & $54(n=40)$ & 0.096 \\
\hline Age in years, mean $\pm S D$ & $52 \pm 9$ & $52 \pm 14$ & 0.64 \\
\hline Gender & & & 0.65 \\
\hline Male, \% & 86 & 70 & \\
\hline Female, \% & 14 & 30 & \\
\hline PRA level T cell prior to HTx & $0.07 \pm 0.1$ & $0.05 \pm 0.06$ & 0.99 \\
\hline PRA level B cell prior to HTx & $0.05 \pm 0.08$ & $0.03 \pm 0.05$ & 0.81 \\
\hline \multicolumn{4}{|l|}{ Outcomes after Heart Transplantation } \\
\hline Length of Hospital Stay, mean \pm SD & $45 \pm 43$ & $27 \pm 21$ & 0.42 \\
\hline Complications before discharged, $\%$ & 71 & 41 & 0.22 \\
\hline Reoperation, \% & 57 & 15 & 0.03 \\
\hline Bleeding, \% & 14 & 3 & 0.28 \\
\hline Infection, \% & 29 & 20 & 0.6 \\
\hline Stroke, \% & 0 & 3 & 1 \\
\hline Renal Failure, \% & 14 & 5 & 0.39 \\
\hline Primary Graft Failure, \% & 0 & 5 & 1 \\
\hline Rejection Episodes (R2 or higher), mean \pm SD & $0.71 \pm 1.89$ & $0.68 \pm 1.14$ & 0.37 \\
\hline Complications requiring readmission, $\%$ & 71 & 63 & 1 \\
\hline
\end{tabular}

BTT: Bridge to Transplantation; PRA: Panel-Reactive Antibody.

\section{Patient Survival After Heart Tx}

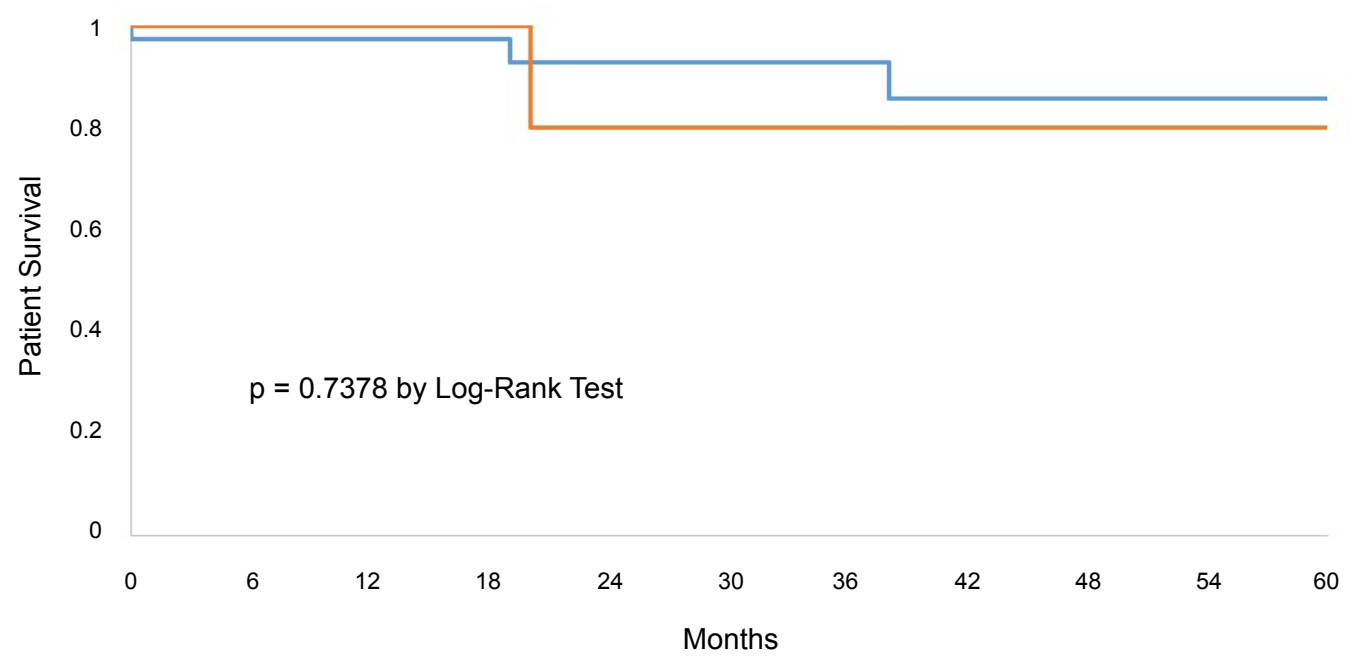

$-\mathrm{BMI}<35-\mathrm{BMI} \geq 35$

Figure 1: Kaplan Meier curve depicting patient survival after heart transplantation. Two patients in BMI < 35 group and one patient in BMI $\geq 35$ group died during followup period.

40 were in $\mathrm{BMI}<35$ groups. Age, gender, race, and panel-reactive antibody (PRA) levels were comparable between the two groups. There was not a significant change in BMI before LVAD and before Htx. After HTx, patients with a BMI $\geq$ 35 had a significantly higher prevalence of reoperation ( $57 \%$ vs. $15 \% ; p=0.03$ ). All other outcomes after HTx were compa- rable between both groups, including infection, stroke, renal failure, primary graft failure and complications requiring readmission. HTx survival and graft survival were comparable in both groups (Figure 1). The 1, 3, and 5-year survival by Kaplan Meier analysis was $100 \%, 80 \%, 80 \%$ for the morbidly obese and $97 \%, 93 \%, 85 \%$, for the non-morbidly obese groups, with 


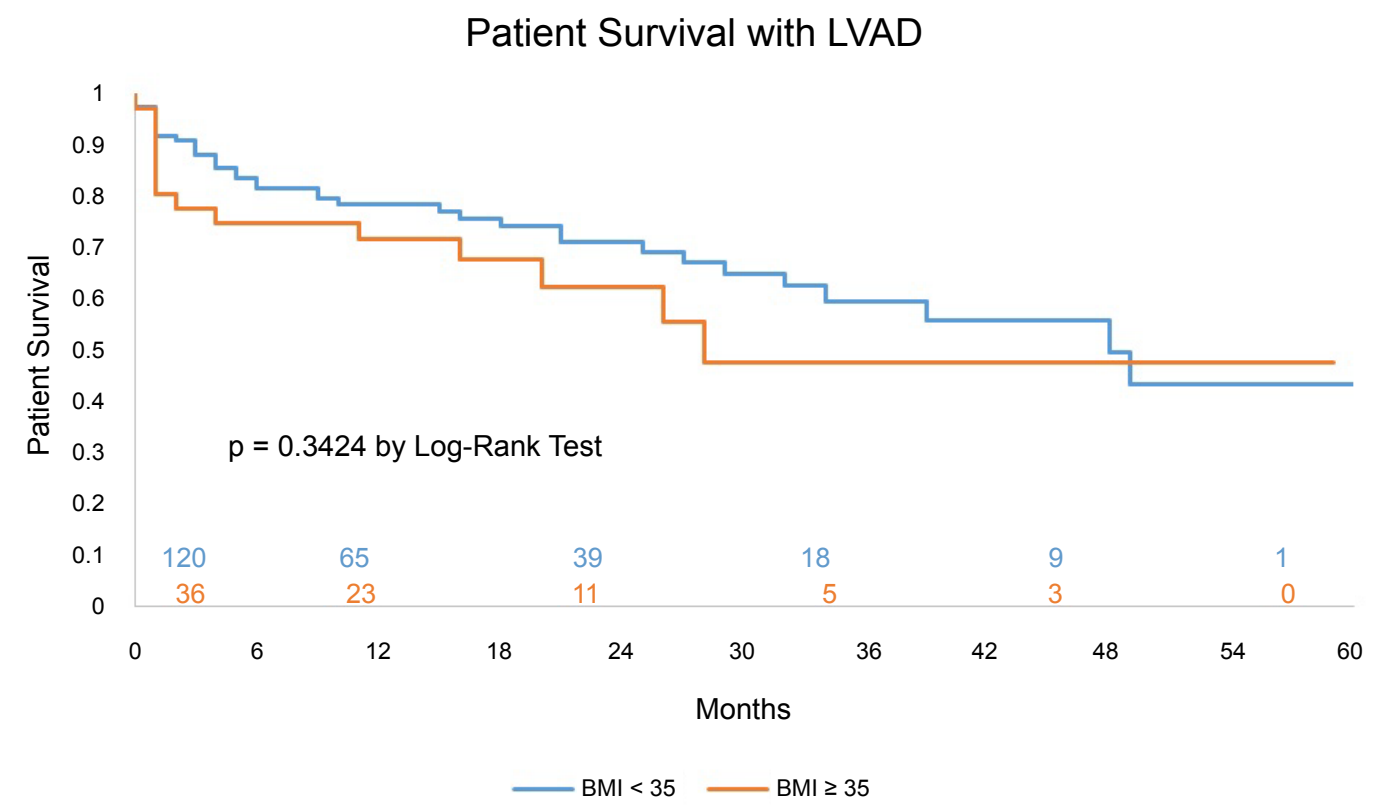

Figure 2: Kaplan Meier curve depicting patient survival with CF-LVAD. Curve has been censored for heart transplantation.

a $p$ value of 0.30

Survival of LVAD patients irrespective of VAD designation (BTT and DT) at 1, 3 and 5years by Kaplan Meier analysis was $71 \%, 47 \%, 47 \%$ respectively for the morbidly obese and $78 \%$, $59 \%, 43 \%$ respectively for the non-morbidly obese, with a $p$ value of 0.30 (Figure 2).

\section{Discussion}

We examined the clinical outcomes in patients with and without morbid obesity, supported with LVADs, who either did or did not receive a HTx. There were several main findings in our study. First, at the time of LVAD placement, morbidly obese patients were of younger age, had fewer prior myocardial infarctions and had fewer CABG surgeries. Second, post-operative LVAD complications were similar between groups with the exception that morbidly obese patients had more bleeding requiring reoperation. Third, device related complications were similar between both BTT groups, with the exception that morbidly obese patients trended towards increased device thrombosis and hemolysis. Fourth, in this selected group of morbidly obese patients the immediate and long-term survival after LVAD and after heart transplantation is comparable to the non-morbidly obese group.

We based our definition of morbid obesity as per the $\mathrm{Na}$ tional Institutes of Health directive [14]. In general, morbid obesity is designated for a person with a BMI of $>40$. However, the presence of a significant comorbidity such as advanced heart failure imparts a similar designation at a BMI of $\geq 35$ [14]. We acknowledge the unequivocal benefits of weight loss in obese patients and do offer various programs to help our obese patients lose weight. However, despite these efforts, our rate of LVAD placement in morbidly obese patients is higher (23\%) compared to reported rates in the literature that ranged from $2.7 \%$ to $20 \%$ [13,15-17]. The higher prevalence of morbidly obese patients supported with LVAD at our cen- ter is reflective of relatively liberal patient selection criteria and also due to our patient demographics. Similarly, our rate of HTx in morbidly obese patients is higher (32\%) compared to reported rates in the literature that ranged from $3.5 \%$ to $10 \%$ [10-13]. The average BMI in our morbidly obese group was $41.6 \pm 5.5$, which is higher than that of other studies, with averages of $38 \pm 2.6$ [17], $38.3 \pm 4.1$ [12], and $35.3 \pm 4.9$ [11]

Before LVAD placement, there were certain favorable patient attributes in the morbidly obese group. They were younger by almost a decade compared to the non-morbidly obese group ( $47 \pm 12.7$ vs. $55 \pm 13.4$ years) and had fewer prior myocardial infarctions, arrhythmias and previous CABG surgeries $[17,18]$. This selection bias was also noted in other studies where relatively younger aged morbidly obese patients were supported with LVAD compared to nonmorbidly obese patients $[13,15]$. We recognized significantly higher right heart catheterization pressures in morbidly obese patients compared to non-morbidly obese patients, which was also noted by other investigators [12,13,15]. A high prevalence of sleep apnea and perhaps reactive pulmonary vasculature in morbidly obese patients leads to higher rightsided heart pressures. LVAD support, which unloads the left ventricle and decreases pulmonary artery pressure, is a valuable intervention prior to HTx to prevent potential right heart failure after HTx.

One major concern in offering LVAD support to patients with morbid obesity is the increased risk of postoperative complications [15]. However, after LVAD implantation, we did not find that morbidly obese patients had higher postoperative complications, such as post-operative stroke, new onset renal failure, multi-system organ failure or hospital mortality. We did find that postoperative bleeding following LVAD implantation was more prevalent in morbidly obese patients ( $42 \%$ vs. $22 \%, p=0.03)$, which was also observed by Butler, et al. [16] While postoperative bleeding is a well 
characterized complication in patients with very low BMI undergoing LVAD implantation $[15,18]$, (likely secondary to malnutrition and clotting factor deficiency) the reasons for increased bleeding in morbidly obese patients remains unclear especially since we followed a similar anticoagulation protocol for all LVAD patients with an INR target goal of 2-3. Nonetheless, meticulous attention to hemostasis and correction of coagulopathy is critical in this group of patients to reduce postoperative bleeding.

Published data on device specific complications in morbidly obese patients is mixed, as was noted in our study; some studies suggest increased complications in morbidly obese patients $[15,19-21]$, while others found similar complication rates irrespective of BMI $[17,22]$. As shown in other studies, morbidly obese patients after LVAD had more recurrent driveline infections and trended towards increased thrombosis and hemolysis. It is also well recognized that a larger BMI is a risk factor for pump thrombosis $[15,19,23]$. While the exact mechanism behind this process is unknown, one hypothesis is that obesity promotes a prothrombotic environment by increasing both platelet activation and expression of plasminogen activator inhibitor-1 and tissue factor [24], all of which could lead to increased risk of LVAD thrombosis.

Multiple studies have shown that post LVAD survival in morbidly obese patients is comparable to non-morbidly obese patients $[13,15-17,20]$. We noticed similar observations in our study. This could be due to the younger age and fewer comorbidities in the morbidly obese patients. Brewer, et al. found that after accounting for age by the cox proportional hazard model, the 1-year survival with LVAD support in the morbidly obese group dropped by $10 \%$ [15]. Therefore, the LVAD outcome results in morbidly obese patients still need to be interpreted with caution, and without making generalizations.

In our study, LVAD designation as BTT was comparable between the morbidly obese and non-morbidly obese groups. Morbidly obese patients spent an average of 216 more days on the HTx waiting list ( $619 \pm 372$ vs. $403 \pm 342$ days), however this difference did not attain statistical significance $p=$ 0.1. A similar observation was made by Weiss, et al. in which morbidly obese patients spent an average of 199.8 more days on the waiting list $(453.9 \pm 613.4$ vs. $254 \pm 469.3$ days, $p<$ $0.05)$ [12]. We believe that the relatively longer wait times were primarily driven by the need for appropriate donor recipient size matching. Longer wait times with LVAD support can increase device specific complications that can negatively influence $H T x$ outcomes $[12,25]$.

Morbidly obese patients trended towards receiving fewer HTxs, (32\% vs. $54 \% p=0.096)$; this was also observed by other published studies $[12,13]$. Due to the smaller number of patients in the morbidly obese group receiving HTx $(n=$ 7), a comparison to the non-morbidly obese group $(n=40)$ may not be very accurate. Nonetheless, except for increased reoperation, the post $\mathrm{HTx}$ outcomes between the two groups was comparable, including stroke, renal failure and sepsis. We did not find a higher prevalence of rejection episodes in morbidly obese patients, which is similar to some studies

\section{$[7,9,10]$, but different from others $[8,11]$.}

Literature on post HTx intermediate and long-term survival in morbidly obese patients is mixed with a majority of studies suggesting inferior survival outcomes [7,10-13] and a minority suggesting comparable outcomes [9] to non-morbidly obese patients. In our study, morbidly obese patients had comparable post HTx survival when compared to non-morbidly obese patients at 1,3 , and 5 years $(100 \%$, $80 \%, 80 \%$ vs. $97 \%, 93 \%, 85 \%$ respectively, $p=0.30$ ). While we do not have a simple answer to explain these comparable post-HTx outcomes in morbidly obese patients, a finding that is uncommon amongst currently published literature, we speculate the following observations. Our morbidly obese group was very small, and likely diminished the odds of being an equivalent comparison group. In addition, unlike our study, previous studies compared morbidly obese patients (BMI > 35) to those who had a normal BMI (18.5-24.99).

\section{Limitations}

This is a retrospective study and certain limitations inherent to retrospective studies are inevitable. Moreover, this is a single center study based on a relatively small sample of patients; hence we cannot generalize the results to larger populations. Due to the smaller sample size, in particular within the morbidly obese group, as well as the discrepancy in the size between the groups, we were precluded from performing sophisticated statistical analysis. Some of the trends we saw may not have reached statistical significance because our study was underpowered, leading to type II error. Due to selection bias in the morbidly obese group the clinical outcomes could be better than expected. Despite these limitations we believe the strengths of our study were that we were able to focus on an understudied population; we followed patients from LVAD through HTx that had consistent perioperative management.

\section{Conclusions}

In carefully selected morbidly obese patients, LVAD implantation and HTx outcomes are comparable. Morbid obesity in isolation should not be a contraindication for LVAD support or HTx. In the future, it would be beneficial to study these outcomes with a multicenter study, through using the INTERMACS and United Network for Organ Sharing (UNOS) databases.

\section{References}

1. Mozaffarian D, Benjamin EJ, Go AS, et al. (2016) Executive summary: heart disease and stroke statistics-2016 update: A report from the American heart association. Circulation 133: 447-454.

2. Taylor DO, Edwards LB, Aurora P, et al. (2008) Registry of the International Society for Heart and Lung Transplantation: Twenty-fifth official adult heart transplant report-2008. J Heart Lung Transplant 27: 943-956.

3. Miller LW, Pagani FD, Russell SD, et al. (2007) Use of a continuousflow device in patients awaiting heart transplantation. N Engl J Med 357: 885-896.

4. Pagani FD, Miller LW, Russell SD, et al. (2009) Extended 
mechanical circulatory support with a continuous-flow rotary left ventricular assist device. J Am Coll Cardiol 54: 312-321.

5. Feldman D, Pamboukian SV, Teuteberg JJ, et al. (2013) The 2013 International Society for Heart and Lung Transplantation Guidelines for mechanical circulatory support: executive summary. J Heart Lung Transplant 32: 157-187.

6. Mehra MR, Canter CE, Hannan MM, et al. (2016) The 2016 International Society for Heart Lung Transplantation listing criteria for heart transplantation: A 10-year update. J Heart Lung Transplant 35: 1-23.

7. Grady KL, White-Williams C, Naftel D, et al. (1999) Are preoperative obesity and cachexia risk factors for post heart transplant morbidity and mortality: A multi-institutional study of preoperative weight-height indices. J Heart Lung Transplant 18: 750-763.

8. Lietz K, John R, Burke EA, et al. (2001) Pretransplant cachexia and morbid obesity are predictors of increased mortality after heart transplantation. Transplantation 72: 277-283.

9. Macha M, Molina EJ, Franco M, et al. (2009) Pre-transplant obesity in heart transplantation: Are there predictors of worse outcomes? Scand Cardiovasc J 43: 304-310.

10. Nagendran J, Moore MD, Norris CM, et al. (2016) The varying effects of obesity and morbid obesity on outcomes following cardiac transplantation. Intl J Obesity 40: 721-724.

11. Russo MJ, Hong KN, Davies RR, et al. (2010) The effect of body mass index on survival following heart transplantation: Do outcomes support consensus guidelines? Annals Surg 25: 144-152.

12. Weiss ES, Allen JG, Russell SD, et al. (2009) Impact of recipient body mass index on organ allocation and mortality in orthotopic heart transplantation. J Heart Lung Transplant 28: 1150-1157.

13. Clerkin KJ, Naka Y, Mancini DM, et al. (2016) The impact of obesity on patients bridged to transplantation with continuousflow left ventricular assist devices. JACC Heart Fail 10: 761-768.

14. (1991) NIH conference. Gastrointestinal surgery for severe obesity. Consensus development conference panel. Ann Intern Med 12: 956-961.
15. Brewer RJ, Lanfear DE, Sai-Sudhakar CB, et al. (2012) Extremes of body mass index do not impact mid-term survival after continuous-flow left ventricular assist device implantation. J Heart Lung Transplant 31: 167-172.

16. Butler J, Howser R, Portner PM, et al. (2005) Body mass index and outcomes after left ventricular assist device placement. Ann Thorac Surg 79: 66-73.

17. Musci M, Loforte A, Potapov EV, et al. (2008) Body mass index and outcome after ventricular assist device placement. Ann Thorac Surg 86: 1236-1242.

18. Go PH, Nemeh HW, Borgi J, et al. (2016) Effect of body mass index on outcomes in left ventricular assist device recipients. J Card Surg 31: 242-247.

19. Kirklin JK, Naftel DC, Pagani FD, et al. (2015) Pump thrombosis in the Thoratec HeartMate II device: An update analysis of the INTERMACS Registry. J Heart Lung Transplant 34: 1515-1526.

20. Mohamedali B, Yost G, Bhat G (2015) Obesity as a risk factor for consideration for left ventricular assist devices. J Cardiac Failure 21: 800-805.

21. Raymond AL, Kfoury AG, Bishop CJ, et al. (2010) Obesity and left ventricular assist device driveline exit site infection. ASAIO J 56: 57-60.

22. Martin SI, Wellington L, Stevenson KB, et al. (2009) Effect of body mass index and device type on infection in left ventricular assist device support beyond 30 days. Interact Cardiovasc Thorac Surg 11: 20-23.

23. Smedira NG, Blackstone EH, Ehrlinger J, et al. (2015) Current risks of HeartMate II pump thrombosis: Non-parametric analysis of Interagency Registry for Mechanically Assisted Circulatory Support data. J Heart Lung Transplant 34: 1527-1534.

24. Samad F, Ruf W (2013) Inflammation, obesity, and thrombosis. Blood 122: 3415-3422.

25. Quader MA, Wolfe LG, Kasirajan V (2015) Heart transplantation outcomes in patients with continuous-flow left ventricular assist device-related complications. J Heart Lung Transplant 34: 75-81.

DOI: $10.36959 / 338 / 329$

Copyright: (C) 2019 Cohen SE, et al. This is an open-access article distributed under the terms of the Creative Commons Attribution License, which permits unrestricted use, distribution, and reproduction in any medium, provided the original author and source are credited. 